\title{
Thymidylate synthase expression in oral squamous cell carcinoma predicts response to $S-1$
}

\author{
KOJI HARADA, YUICHIRO KAWASHIMA, HIDEO YOSHIDA and MITSUNOBU SATO \\ Therapeutic Regulation for Oral Tumor, Institute of Health Bioscience, University of \\ Tokushima Graduate School, 3-18-15 Kuramoto-cho, Tokushima 770-8504, Japan
}

Received December 6, 2005; Accepted January 31, 2006

\begin{abstract}
The purpose of this research was to evaluate the predictive value of expression of thymidylate synthase (TS), dihydropyrimidine dehydrogenase (DPD), thymidine phosphorylase (TP), or orotate phosphoribosyltransferase (OPRT) genes for response to $\mathrm{S}-1$. Twenty-five patients with oral squamous cell carcinoma (OSCC) received S-1 $80 \mathrm{mg} / \mathrm{m}^{2} /$ day. Pretreatment tumor biopsies were analyzed for TS, DPD, TP or OPRT mRNA expression by real-time reverse transcriptionPCR. TS protein expression was evaluated by immunohistochemistry using a polyclonal TS antibody. Twenty-five patients were evaluable for response and gene expression. Six of the $25(24 \%)$ achieved complete remission and 4 of the $25(16 \%)$ had a partial response. Median TS/ß-actin was 2.51 (range $0.98-7.07)$. Median TS/ $\$$-actin was 1.26 in responding patients and 3.43 in non-responders $(\mathrm{P}=0.0001)$. Ten of 11 patients with TS/B-actin $<1.80$ and 0 of 15 with higher values responded $(\mathrm{P}<0.0001)$. Overall survival was 29.7 months in patients with TS/ß-actin $<1.80$ and 41.7 months in patients with higher values $(\mathrm{P}=0.0013)$. No correlations were seen between expression of DPD, TP or OPRT mRNA and response or survival. Weak TS staining was seen in 6 of 25 tumors evaluable for immunohistochemistry, including 5 responders. All 4 of the patients with both weak staining and TS/B-actin $<1.80$ responded. High TS mRNA expression predicts non-response to S-1. On the other hand, high levels of DPD or TP mRNA and low levels of OPRT mRNA are not associated with S-1 resistance. TS mRNA expression is considered to be a useful prognostic factor in OSCC patients with S-1 single-agent therapy.
\end{abstract}

\section{Introduction}

Oral squamous cell carcinoma (OSCC) along with pharyngeal carcinoma, which is the sixth most common cancer in the

Correspondence to: Dr Koji Harada, Therapeutic Regulation for Oral Tumor, Institute of Health Bioscience, University of Tokushima Graduate School, 3-18-15 Kuramoto-cho, Tokushima 770-8504, Japan E-mail: harako@dent.tokushima-u.ac.jp

Key words: S-1, predictive factor, thymidylate synthase, oral squamous cell carcinoma world (1). OSCC is a significant public health problem throughout the world because oral function is very important for breathing, eating and conversation. Despite recent advances in surgery, radiotherapy, chemotherapy and immunotherapy, the mortality rate of OSCC is below $50 \%$ in the advanced stage $(2,3)$. Also, enlarged operation or systemic chemotherapy is not often suitable for patients of advanced age or with complications. In order to improve the prognosis of patients with OSCC, the development of new, effective chemotherapeutic agents is necessary.

S-1 is a novel orally administered anticancer drug that is a combination of tegafur (FT), 5-chloro-2, 4-dihydroxypyridine (CDHP) and oteracil potassium (Oxo) in a 1:0.4:1 molar concentration ratio (4). 5-Chloro-2,4-dihydroxypyridine is a competitive inhibitor of dihydropyrimidine dehydrogenase, which is involved in the degradation of 5-fluorouracil (5-FU), and acts to maintain efficacious concentrations of 5-FU in plasma and tumour tissues (5). Oteracil potassium, a competitive inhibitor of orotate phosphoribosyltransferase, inhibits the phosphorylation of 5-FU in the gastrointestinal tract, reducing the serious gastrointestinal toxicity associated with 5-FU (6). S-1 therapy in athymic nude rats was associated with the retention of a higher and more prolonged concentration of 5-FU in plasma and tumor tissues, when compared with Tegafur/Uracil (UFT) (7). The antitumor effect of S-1 has been already demonstrated in a variety of solid tumors: the response rates for advanced gastric cancer (8), colorectal cancer (9), non-small-cell lung cancer (10) and head and neck cancer (11) in the late phase II studies conducted in Japan were 44-49, 35, 22 and 29\%, respectively. The efficacy of S-1 for the treatment of gastrointestinal cancer has also been reported in European patients: the response rates for advanced gastric cancer (12) and colorectal cancer (13) were 32 and 24\%, respectively. However, few previous reports have described the efficacy and safety of S-1 for the treatment of oral cancer (14). Moreover, the predictive factor of the success of treatment with $\mathrm{S}-1$ has not been clarified yet.

Retrospective studies of OSCC sections with immunohistochemistry (IHC) showed that the degree of TS and DPD protein expression predicted the survival, with higher expression having an adverse effect $(15,16)$. This was also demonstrated in various cancers (17). Additional studies have shown that high levels of expression of TP (18) and DPD, the rate-limiting enzyme in the catabolic degradation of 5-FU (19), are also predictors of 5-FU treatment failure. No previous reports have described the predictive value of OPRT in OSCC with S-1. 
Table I. Clinical characteristics.

\begin{tabular}{lc}
\hline Characteristics & Total $(\mathrm{n}=25)$ \\
\hline Age (mean) & $39-99(69.3)$ \\
Sex (M:F) & $15: 10$ \\
T classification & \\
T2 & 17 \\
T3 & 7 \\
T4 & 1 \\
N classification & \\
N (-) & 20 \\
N (+) & 5 \\
Stage & \\
II & 13 \\
III & 9 \\
VI & 3 \\
Therapeutic effect & \\
CR & 6 \\
PR & 4 \\
MR & \\
Outcome & \\
Alive & \\
Dead & \\
\hline
\end{tabular}

NS, not significant; M, F: male, female. For definitions of complete response (CR), partial response (PR), and minor response (MR) see Materials and methods. T, N and stage grouping were classified according to the 1997 International Union Against Cancer criteria.

The aims of this study were to investigate the influence of levels of expression of TS, DPD, TP and OPRT on response to $\mathrm{S}-1$. In addition, it was proposed to examine the relationship between TS mRNA and protein expression in pretreatment biopsies of OSCC, and to correlate these with response to S-1.

\section{Patients and methods}

Eligibility. Patients were eligible for this study if they had a histological diagnosis of OSCC. In addition, patients were required to have normal platelet counts and blood clotting, and a life expectancy of at least 3 months. Patients were not suitable if they had received adjuvant systemic 5-FU treatment for primary disease within 12 months before study entry or any systemic treatment. Clinical data on patient age, sex, T classification, $\mathrm{N}$ classification, stage of disease, therapeutic effect and outcome were shown in Table I.

Pretreatment evaluation. Baseline full blood count, urea and electrolytes, liver function tests, coagulation studies, and tumor markers (SCC and CEA) were investigated. A CT scan was performed for detecting the metastatic disease or the local invasiveness. If the results of all examinations were suitable, patients gave informed written consent and were entered in the study, which was approved by the Research and Ethics Committees of the Tokushima University Hospital.

Treatment. S-1 was administered orally at a dose of $40 \mathrm{mg} / \mathrm{m}^{2}$ twice daily after breakfast and dinner. Three initial doses were established according to the body surface area (BSA) as follows: $\mathrm{BSA}<1.25 \mathrm{~m}^{2}, 80 \mathrm{mg} /$ day; $1.25 \mathrm{~m}^{2}<\mathrm{BSA}<1.50 \mathrm{~m}^{2}$, $100 \mathrm{mg} /$ day; and BSA>1.50 m², $120 \mathrm{mg} /$ day. S-1 was administered at the respective dose for 28 days, followed by a 14-day rest period; this treatment course was repeated until the occurrence of disease progression or unacceptable toxicities, or the patient's refusal to continue. When a grade 3 or greater haematological or non-haeamatological toxicity occurred, the temporary interruption of the S-1 administrations was allowed until the toxicity subsided to grade 1 or less (Common Terminology Criteria for Adverse Events Ver.3.0). If the daily dose of S-1 was considered to be intolerable, the retreatment dose was reduced by $20 \mathrm{mg} /$ day (minimum dose, $60 \mathrm{mg} /$ day). If a rest period of more than 28 days was required because of toxicity, the patient was withdrawn from the study. Patients were not allowed to receive concomitant radiation therapy or chemotherapy during the study. Patients maintained a daily journal to record their intake of S-1 and any signs or symptoms that they experienced.

Assessment of response. Assessments of response were performed by direct measurement. Tumor response after therapy for 4 weeks or more was defined as follows: complete remission $(\mathrm{CR})$ is the disappearance of all lesions and no occurrence of new lesions, partial response $(\mathrm{PR})$ is the reduction of $\geq 50 \%$ of lesions and no occurrence of new lesions, minor response (MR) is the reduction of $50-25 \%$ lesions and no occurrence of new lesions, and no change (NC) is the reduction of $\leq 25 \%$ of lesions without occurrence of new lesions.

\section{Laboratory analyses}

Microdissection. A representative formalin-fixed, paraffinembedded tumor specimen, which contained a central section of the cancer, was selected from each of the lesions by a pathologist after examination of the hematoxylin and eosinstained slides. Ten- $\mu \mathrm{m}$-thick sections were stained with nuclear fast red to enable visualization of histology for lasercaptured microdissection (PALM Microlaser Technologies, Munich, Germany), which was performed to ensure malignant cells and normal stromal cells were studied.

RNA extraction and cDNA synthesis from paraffin-embedded tissues. RNA was extracted according to the method of Chomczynski et al with minor modifications (22). Briefly, $600 \mu 1$ of xylene was added to each tube. After centrifugation for $7 \mathrm{~min}$ at $20,800 \mathrm{~g}$, the supernatant was discarded, and the washing step was repeated 3 times. The deparaffinized materials were rehydrated in xylene:ethanol:water at the following ratios: 95:95:5, 95:90:10, 95:80:20, 95:75:25 and 95:70:30. After each step, the rehydration medium was removed after centrifugation for $7 \mathrm{~min}$ at 20,800 g. After discarding the last supernatant, the pelleted sections were resolved in $70 \%$ ethanol. Then, $400 \mu 1$ of buffer ( $4 \mathrm{M}$ 
guanidine isothiocyanate solution including $0.5 \%$ sarcosine and $8 \mu \mathrm{l}, 1 \mathrm{M}$ DTT) were added to the dried tissue and homogenized mechanically. For RNA demodification, homogenates were heated at $95^{\circ} \mathrm{C}$ for $30 \mathrm{~min}$. RNA was extracted from homogenates by the addition of $50 \mu 1$ of $2 \mathrm{M}$ sodium acetate ( $\mathrm{pH} 4.0), 500 \mu 1$ of water-saturated phenol and $100 \mu \mathrm{l}$ of chloroform-isoamyl mixture (49:1). RNA was recovered from the water phase by isopropanol precipitation and transferred to a new tube and precipitate with $10 \mu 1$ glycogen and $400 \mu \mathrm{l}$ isopropanol for $30 \mathrm{~min}$ at $-20^{\circ} \mathrm{C}$. After centrifuging for $7 \mathrm{~min}$ at $20,800 \mathrm{~g}$, the pellet was washed with $500 \mu 175 \%$ ethanol. After drying, the pellet was dissolved in $50 \mu 15 \mathrm{mM}$ Tris- $\mathrm{HCl}$ ( $\mathrm{pH} 8.0)$. Reverse transcription was carried out at $39^{\circ} \mathrm{C}$ for 45 min using 400 units of Moloney murine leukemia virus (MMLV) reverse transcriptase, $1 \mathrm{X}$ first-strand buffer, $0.04 \mu \mathrm{g} / \mu 1$ random hexamers, $10 \mathrm{mM}$ DTT and $1 \mathrm{mM}$ deoxynucleoside triphosphate.

PCR quantification of $m R N A$ expression. Target cDNA sequences were amplified by quantitative PCR using a fluorescence-based real-time detection method (ABI PRISM 7900 Sequence Detection System, TaqMan; Applied Biosystems, Foster City, CA, USA). PCR was carried out for each gene of interest and $B$-actin was used as an internal reference gene. The $25-\mu 1 \mathrm{PCR}$ reaction mixture contained $600 \mathrm{nmol} / \mathrm{l}$ of each primer, $200 \mathrm{nmol} / 1$ each of dATP, dCTP and dGTP, $400 \mathrm{~mol} / \mathrm{l} \mathrm{dUTP}, 5.5 \mathrm{mmol} / \mathrm{i} \mathrm{MgCl}_{2}$ and $1 \mathrm{X}$ TaqMan Buffer A containing a reference dye (all reagents were purchased from Applied Biosystems). The primers and probe sequences were as follows: TS primers, GCCTCGGTGTGCCTTTCA and CCCGTGATGTGCGCAAT, probe 6FAM (carboxyfluorescein)-5-TCGCCAGCTACGCCCTGCTCA-3TAMRA (N,N, $\mathrm{N}, \mathrm{N}$-tetramethyl-6carboxyrhodamine); DPD primers, AGGA CGCAAGGAGGGTTTG and GTCCGCCGAGTCCTTAC TGA, probe 6FAM-5-CAGTGCCTACAGTCTCGAGTCTG CCAGTG3TAMRA; TP primers, CCTGCGGACGGAAT CCT and GCTGTGATGAGTGGCAGGCT, probe 6FAMCAGCCAGAGATGTGACAGCCACCGT; OPRT primers, TAGTGTTTTGGAAACTGTTGAGGTT and CTTGCCTCC CTGCTCTCTGT, probe 6FAM-TGGCATCAGTGACCTTC AAGCCCTCCT; and $B$-actin primers, TGAGCGCGGCTAC AGCTT and TCCTTAATGTCACGCACGATTT, probe 6FAM-5-ACCACCACGGCCGAGCGG-3TAMRA. The PCR conditions were $50^{\circ} \mathrm{C}$ for $10 \mathrm{sec}$ and $95^{\circ} \mathrm{C}$ for $10 \mathrm{~min}$, followed by 42 cycles at $95^{\circ} \mathrm{C}$ for $15 \mathrm{sec}$ and $60^{\circ} \mathrm{C}$ for $1 \mathrm{~min}$. Relative gene expression of TS, DPD, TP and OPRT was determined based on the threshold cycles of each gene in relation to the threshold cycle of the corresponding internal standard $\beta$-actin.

The use of $B$-actin as a reference gene removes the need for RNA concentration measurement. The $B$-actin real-time PCR analysis also estimated the amount of extracted mRNA. The rise of the $B$-actin signal after cycle 37 using the described conditions indicated an insufficient amount of mRNA for the subsequent TS, DPD, TP and OPRT quantitation. When measuring gene expression in paraffin-embedded tissues, the median value of the threshold cycle of $\beta$-actin was 26 cycles, ranging from 23 to 28 , in malignant tissues.

$I H C$. The avidin-biotin complex immunohistochemical technique was used to detect TS in tissue specimens, using the
Vectastain ABC kit (Vector Laboratories Inc., Burlingame, CA, USA). Paraffin-embedded tissue sections of $4 \mu \mathrm{m}$ thick were deparaffinized in xylene and rehydrated through graded alcohols. Endogenous peroxidase was quenched with $0.3 \%$ hydrogen peroxide/methanol mixture for $30 \mathrm{~min}$. Sections were rinsed and preincubated with $2 \%$ blocking serum for $30 \mathrm{~min}$, followed by incubation with a TS polyclonal antibody (obtained from Taiho Pharmaceutical Co., Ltd., Tokyo, Japan) for $8 \mathrm{~h}$ at $4^{\circ} \mathrm{C}$. After rinsing the tissue sections in phosphate-buffered saline (PBS) for $10 \mathrm{~min}, 100 \mu \mathrm{l}$ of secondary antibody (biotinylated goat anti-rabbit) was added for $30 \mathrm{~min}$. Tissue sections were again rinsed in PBS for $10 \mathrm{~min}$ and incubated with avidin-biotin complex for $30 \mathrm{~min}$. Sections were rinsed in PBS and incubated with diaminobenzene substrate (Sigma Chemical Co., St. Louis, MO, USA) for $15 \mathrm{~min}$. Tissues were finally rinsed in PBS for $5 \mathrm{~min}$ and tap water for $5 \mathrm{~min}$, and counterstained with Mayer's hematoxylin (Sigma) for $1 \mathrm{~min}$. The tissue sections were subsequently dehydrated in graded ethanol, cleared in Histoclear, and mounted with glass coverslips using DPX (DPX mountant for histology, Sigma). Each run included positive and negative controls.

Scoring of IHC. Tissue sections were examined and scored by three independent observers without knowledge of clinical outcome or RT-PCR results. TS expression was quantitated using a visual grading system based on the intensity of grading (0-3). The highest degree of staining seen in a tumor was used as its score. The mean of the three scores was calculated, and each section was assigned as strong (mean score 1.5) or weak (mean <1.5) staining.

Statistical analysis. The associations between TS, DPD, TP or OPRT gene expression and clinicopathological parameters were assessed using the Mann-Whitney U test. Overall survival was calculated using the method of Kaplan-Meier, and comparison between groups was performed with the log-rank test. Spearman's rank correlation test was used to determine the association between TS IHC score and mRNA expression. All statistical significance was set at $\mathrm{P}<0.05$. Statistical analyses were run using StatView software (version 5.0J, SAS Institute Inc. Cary, NC, USA).

\section{Results}

Twenty-five patients were recruited into this study between June 2001 and December 2002. A median number of 2 cycles of S-1 were given per patient (range 2-3). The median eventfree survival of the entire cohort after S-1 therapy was 4.7 months, whereas the median overall survival was 13.9 months. Nine patients had died at the time of analysis. All twenty-five of the eligible patients had completed treatment with S-1 and all were evaluable for response. There were 10 of 25 responders $(40 \%) ; 6(24 \%)$ achieved complete remission and $4(16 \%)$ had a partial response. All patients were evaluable for both response and gene expression. The responses were evaluated by the pathological records as well as naked eye views.

Tumor TS mRNA expression. Tumor TS: $ß$-actin mRNA ratios were available for 25 patients. The median TS: $\beta$-actin in tumor biopsies was 1.26 (range, 0.98-7.07). For responding patients, 


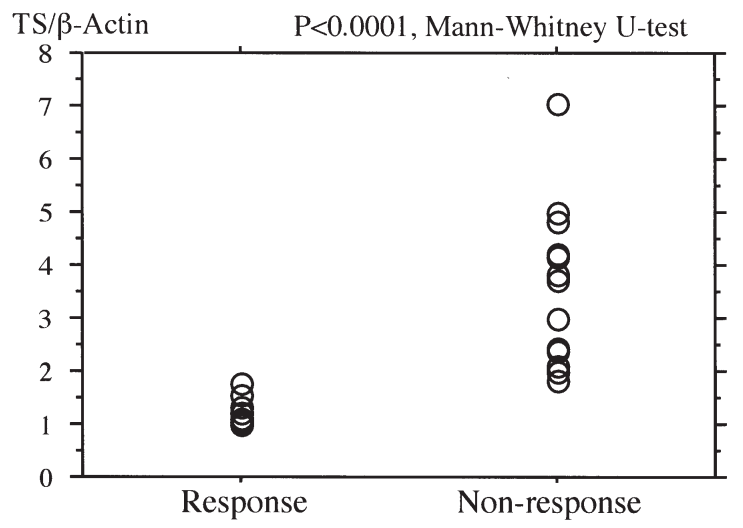

Figure 1. Tumor TS mRNA versus response to S-1.

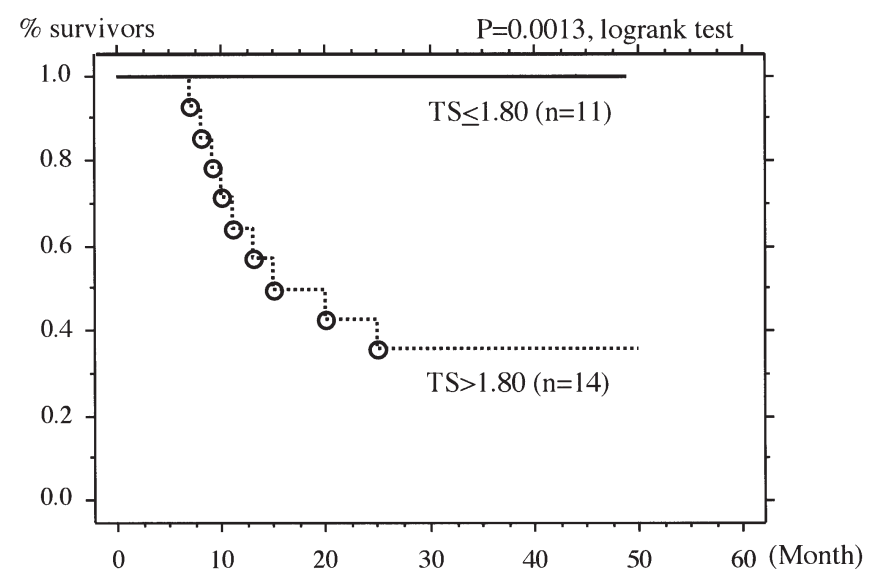

Figure 2. Kaplan-Meier survival curves for patients with high versus low TS mRNA expression.

the median TS: $\beta$-actin was 1.26 compared with 3.43 for nonresponding patients $(\mathrm{P}=0.0001$, Mann-Whitney $\mathrm{U}$ test $)$. Ten of 11 patients with TS: $B$-actin $<1.80$ and 0 of 15 with higher values responded $(\mathrm{P}<0.0001)$. This difference was statistically significant $(\mathrm{P}<0.0001$, Mann-Whitney $\mathrm{U}$ test). Fig. 1 shows the tumor TS mRNA expression according to tumor response.

Tumor TS mRNA expression also correlated with survival: patients with TS: $\beta$-actin ratios $<1.80$ had a median survival time of 41.7 months, whereas patients with TS: $\beta$-actin ratios $>1.80$ had a median survival of 29.7 months $(\mathrm{P}=0.0013)$. Fig. 2 shows the survival curves for these two groups.

Expression of other genes linked to failure of S-1 therapy TP. The median TP:ß-actin was 34.1 (range, 9.38-68.5), and there was considerable overlap in expression between responding and non-responding patients. Interestingly, there was a trend for the median TP to be higher in non-responders (37.5) than responders (28.9), although this was not statistically significant ( $\mathrm{P}=0.174$, Mann-Whitney $\mathrm{U}$ test). These results are illustrated in Fig. 3.

$D P D$. Contrary to our expectation, there was no significant difference in DPD mRNA expression between responders and non-responders, although there was a trend for higher DPD expression in non-responders. The overall median DPD:ß-actin

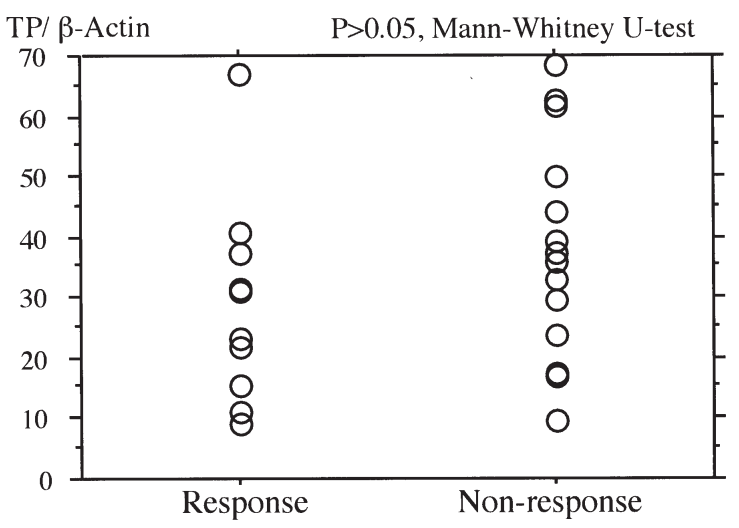

Figure 3. Tumor TP mRNA expression versus response to S-1.

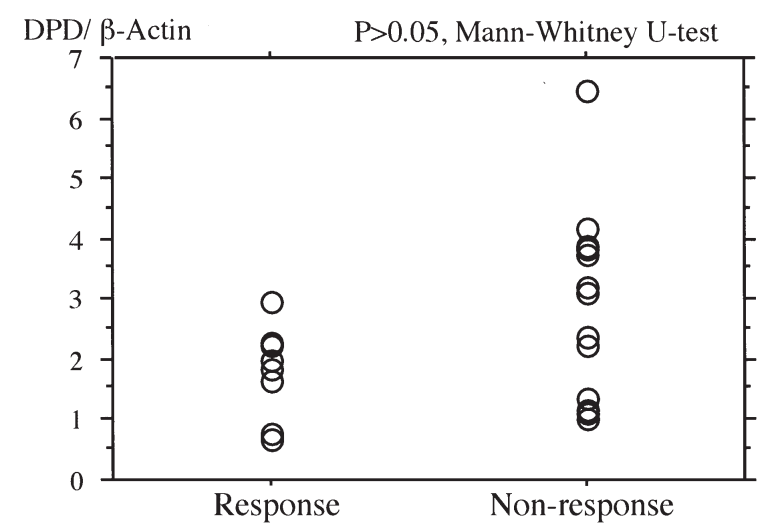

Figure 4. Tumor DPD mRNA expression versus response to S-1.

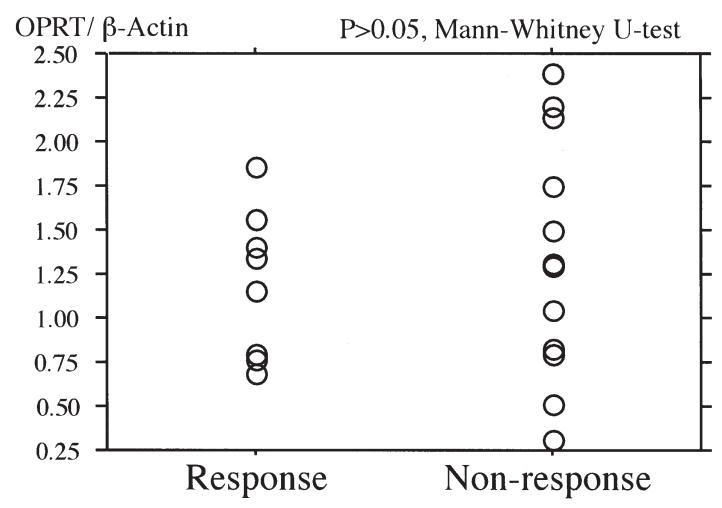

Figure 5. Tumor OPRT mRNA expression versus response to S-1.

was 2.37 (range 0.68-6.46), with medians of 1.81 and 2.75 in responders and non-responders, respectively ( $\mathrm{P}=0.091$, MannWhitney U test), as shown in Fig. 4.

OPRT. The overall median OPRT:ß-actin was 1.20 (range $0.320-2.39)$, with medians 1.11 and 1.27 in responders and non-responders, respectively ( $\mathrm{P}=0.542$, Mann-Whitney $\mathrm{U}$ test). These results are illustrated in Fig. 5.

IHC, as shown in Fig. 6. Strong staining for TS protein was seen in 13 of 25 tumor samples taken before treatment. Of 

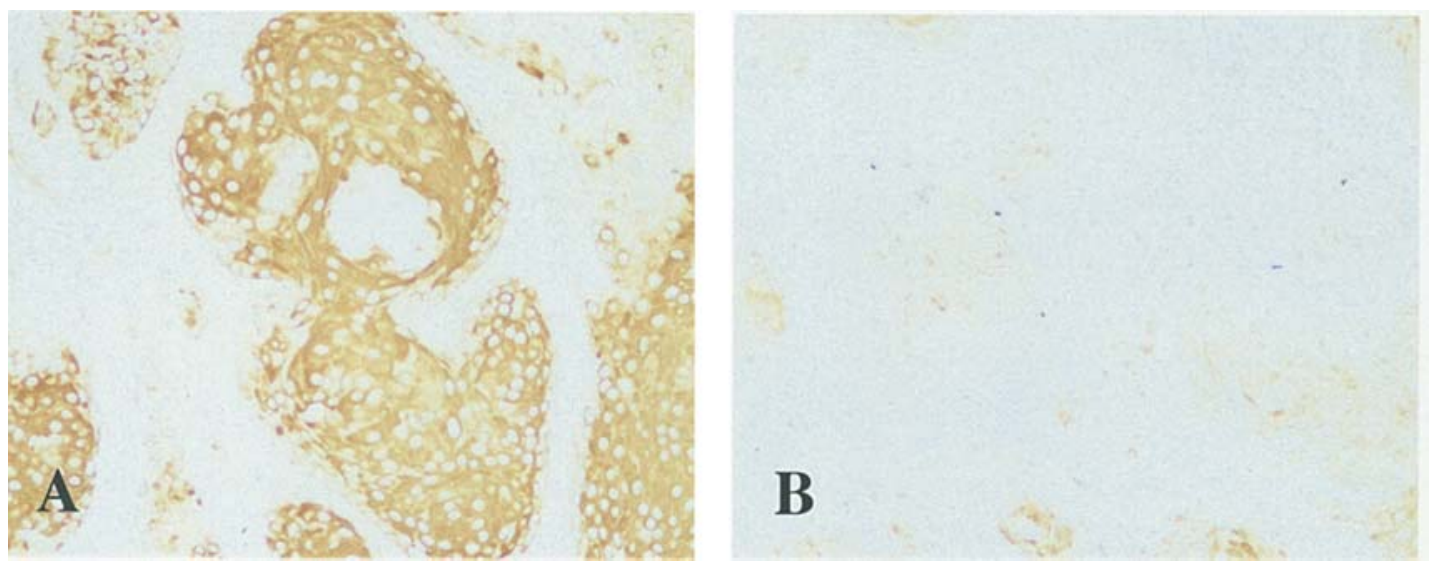

Figure 6. Immunohistochemical staining of TS protein. (A) Strong staining; (B) weak staining.

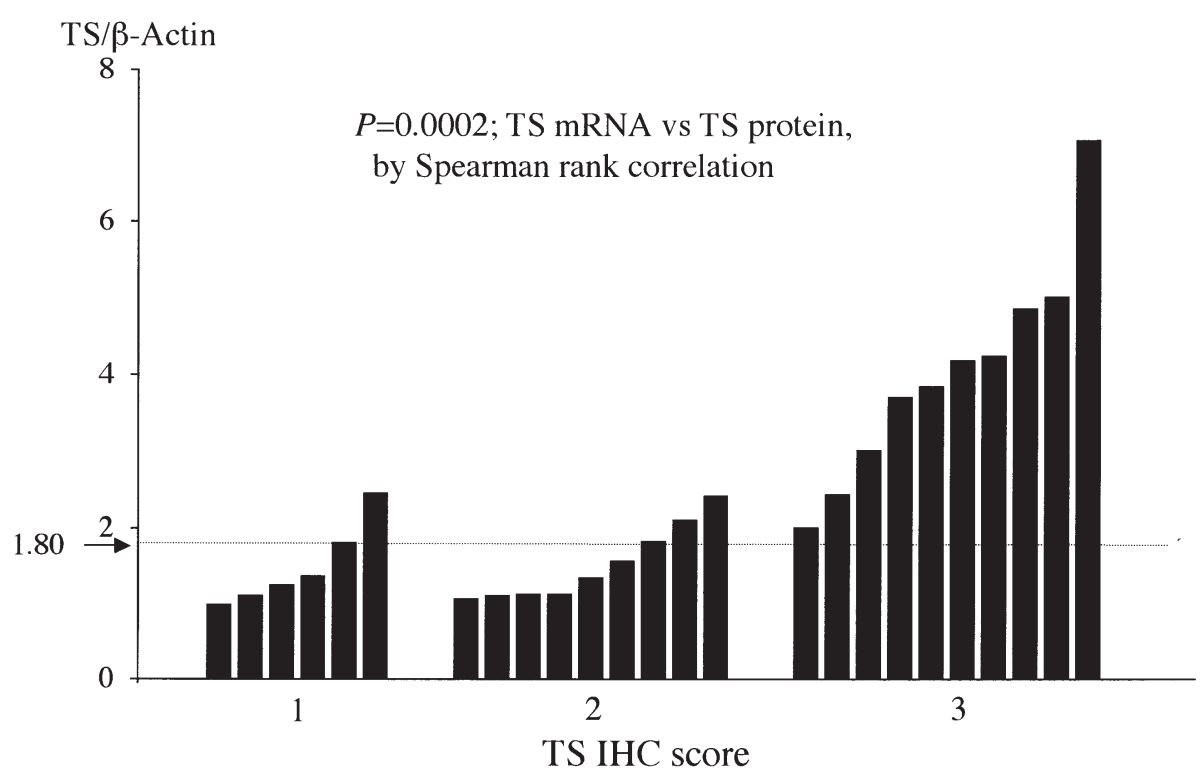

Figure 7. Correlation between TS mRNA (RT-PCR) and protein expression (IHC) in 25 patients with paired data.

the 12 patients with low TS protein, there were 8 responses (66.7\%), compared with 2 of 13 responses (18\%) seen in high TS tumors. Ten of 14 patients with TS: $\beta$-actin $>1.8$ also expressed high levels of protein, whereas lower levels of TS mRNA expression were associated with weak staining for TS protein in 8 of 11 patients. The relationship between TS mRNA and TS protein expression was clear-cut. There was a direct correlation between mean TS IHC score and mRNA expression, as shown in Fig. 7 ( $\mathrm{P}=0.0002$, Spearman's rank correlation test).

\section{Discussion}

OSCC patients of advanced stage or with complications are increasing gradually and enlarged operation or systemic chemotherapy is not often suitable for such patients. As a first-line treatment, S-1 single-agent therapy may be useful for OSCC patients of advanced stage or with complications if we can predict the effect of S-1 on them.

In this study, we have shown a significant correlation between TS mRNA levels in OSCC, response to $S-1$ and patient survival. This result suggested that TS mRNA might be a useful factor for predicting the chemosensitivity to S-1 on OSCC patients. Also, measuring TS gene expression not only can predict response to S-1 but also can identify patients with a better survival prognosis. If these results can be confirmed in a clinical trial with a larger set of patients, data on TS expression in OSCC would permit more rational decisions on whether or not to proceed with S-1-based therapy as a firstline treatment. If the $\mathrm{S}-1$ response indices seem unfavorable, alternative drugs, such as Cisplatin (CDDP) or Docetaxel, (TXT) are now available for treatment of OSCC patients. We have observed that OSCC patients who did not respond to S-1 single-agent therapy responded well to CDDP or TXT. If patients destined for S-1 failure can be identified before the start of treatment, benefits will be gained by avoiding the toxicity associated with the drug. Moreover, it is possible that patients will be more likely to respond to CDDP or TXT when it is given as primary therapy, compared with its use after S-1 failure. Thus, the assignment of patients for either S-1 singleagent therapy or other chemotherapy by taking into consideration their TS mRNA levels may provide a way of achieving 
a substantial increase in the overall response rate to chemotherapy using currently available agents.

Contrary to our expectations, we could not detect the correlation between DPD, TP or OPRT expression and chemosensitivity to $\mathrm{S}-1$. This result may have been due to a sampling bias arising from the heterogeneity of TP, DPD or OPRT expression in tumors because some investigators have clearly indicated that cancers with DPD overexpression did not respond to 5-FU therapy (23). Additional larger studies are needed to determine the clinical relevance of identifying TS, DPD, TP and OPRT expression in OSCC, for the appropriate use of S-1. However, our data suggest that TS mRNA would be a most useful predictor of OSCC chemosensitivity to S-1 when compared with DPD, TP or OPRT mRNA.

Quantification of TS protein must be more important than investigating TS mRNA level because the main mechanism of antitumor activity by $\mathrm{S}-1$ is thought to be inhibition of TS protein through ternary complex (FdUMP/TS/ $\left.\mathrm{CH}_{2} \mathrm{FH}_{4}\right)$ formation. Quantification of TS protein may be the next best technique with the advantage that it is possible to perform IHC on archive material. However, the scoring of tissue sections using visual scales based on intensity and extent of staining are considerably observer-dependent; scores can be influenced by the degree of tissue heterogeneity within the sections, and immuno-positivity gives no indication of the biological activity on the protein. Despite this, Johnston et al showed a close linear relationship between TS gene expression and TS protein expression, and they also showed that both the TS protein level and TS gene expression were significantly associated with response to 5-FU-based therapy, suggesting that TS protein may also be useful as a predictor of colorectal cancer chemosensitivity to S-1 (24). In this study, we found a significant correlation between TS gene expression and TS protein expression. The IHC score of TS protein may be useful as a predictor of OSCC chemosensitivity to S-1. However, TS protein is subject to translational regulation in that the free protein interacts with TS message in a negative feedback loop (25). Also, it has been suggested that polymorphisms of the TS gene, rather than the number of gene copies, may influence the degree of protein expression (26). Moreover, TS is known to be amplified after exposure to chemotherapy, possibly by interruption of the above negative feedback loop (27). We have not yet clarified the degradation or regulation of TS protein. Quantification of TS mRNA using techniques such as microdissection and RT-PCR may be more reliable than quantification of TS protein with IHC score.

The data from this study show a similar correlation between TS expression and response to S- 1 single-agent chemotherapy as has been reported for 5-FU-based therapy. Our data confirm that high TS mRNA expression in biopsies predicts the failure of S-1 therapy. Patients with low TS gene expression should be treated with S-1 single-agent but, if patients have high TS gene expression, we should select alternative currently available agents, such as CDDP or TXT.

\section{Acknowledgements}

This study was supported in part by a Grant-in-Aid from the Japanese Ministry of Education, Science and Culture, Japan.

\section{References}

1. Johnson NW: Epidemiology of oral cancer in risk markers of oral disease. In: Oral Cancer. Vol. 2. Johnson NW (ed). Cambridge University Press, Cambridge, UK, pp3-26, 1991.

2. Inagi K, Takahashi H, Okamoto M, Nakayama M, Makoshi $T$ and Nagai $\mathrm{H}$ : Treatment effects in patients with squamous cell carcinoma of the oral cavity. Acta Otolaryngol Suppl 547: 25-29, 2002.

3. Shingaki S, Takada M, Sasai K, Bibi R, Kobayashi T, Nomura T and Saito C: Impact of lymph node metastasis on the pattern of failure and survival in oral carcinomas. Am J Surg 185: 278-284, 2003

4. Shirasaka T, Shimamoto Y, Ohshimo H, Yamaguchi M, Kato T, Yonekura $\mathrm{K}$ and Fukushima M: Development of a novel form of 5-fluorouracil derivative (S-1) directed to the potentiation of the tumor-selective cytotoxicity of 5-fluorouracil by two biochemical modulators. Anticancer Drugs 7: 548-557, 1996.

5. Tatsumi K, Fukushima M, Shirasaka T and Fujii S: Inhibitory effects of pyrimidine, barbituric acid and pyridine derivatives on 5 -fluorouracil degradation in rat liver extract. Jpn J Cancer Res 78: 748-755, 1987.

6. Shirasaka T, Shimamoto Y and Fukushima M: Inhibition of oxonic acid on gastrointestinal toxicity of 5-fluorouracil without loss of its antitumor activity in rats. Cancer Res 53: 4004-4009, 1993.

7. Shirasaka T, Nakano K, Takechi T, et al: Antitumor effect of $1 \mathrm{M}$ tegafur-0.4 M 5-chloro-2,4-dihydroxypyridine-1 M potassium oxonate (S-1) against human colon carcinoma orthotopically implanted into nude rats. Cancer Res 56: 2602-2606, 1996.

8. Sakata Y, Ohtsu A, Horikoshi N, Sugimachi K, Mitachi Y and Taguchi T: Late Phase II study of novel oral fluoropyrimidine anticancer drug S-1 (1 M tegafur-0.4 M gimestat-1 M otastat potassium) in advanced gastric cancer patients. Eur J Cancer 34: $1715-1720,1998$

9. Ohtsu A, Baba H, Sakata Y, Mitachi Y, Horikoshi N, Sugimachi K and Taguchi T: Phase II study of S-1, a novel oral fluoropyrimidine derivative, in patients with metastatic colorectal carcinoma. Br J Cancer 83: 141-145, 2000.

10. Kawahara M, Furuse K, Segawa Y, Yoshimori K, Matsui K, Kudoh S, Hasegawa K and Niitani H: S-1 Cooperative Study Group (Lung Cancer Working Group), Phase II study of S-1, a novel oral fluorouracil, in advanced non-small-cell lung cancer. Br J Cancer 85: 939-943, 2001.

11. Inuyama Y, Kida A, Tsukuda M, Kohno N and Satake B: Late phase II study of S-1 in patients with advanced head and neck cancer. Gan To Kagaku Ryoho 28: 1381-1390, 2001.

12. Chollet P, Schoffski P, Weigang-Kohler K, et al: EORTC Early Clinical Studies Group.Phase II trial with S-1 in chemotherapynaive patients with gastric cancer. A trial performed by the EORTC Early Clinical Studies Group (ECSG). Eur J Cancer 39: 1264-1670, 2003.

13. Van den Brande J, Schoffski P, Schellens JH, et al: EORTC Early Clinical Studies Group early phase II trial of S-1 in patients with advanced or metastatic colorectal cancer. Br J Cancer 88: 648-653, 2003.

14. Tsukuda M, Kida A, Fujii M, Kono N, Yoshihara T, Hasegawa Y and Sugita M: Chemotherapy Study Group of Head and Neck Cancer. Br J Cancer 93: 884-889, 2005.

15. Kawano K, Goto H, Kanda T and Yanagisawa S: Predictive value of immunohistochemical thymidylate synthase expression for histological response to Tegafur/Uracil (UFT) in oral squamous cell carcinoma. Int J Oral Maxillofac Surg 32: 633-637, 2003.

16. Kawasaki G, Yoshitomi I, Yanamoto S and Mizuno A: Thymidylate synthase and dihydropyrimidine dehydrogenase expression in oral squamous cell carcinoma: an immunohistochemical and clinicopathologic study. Oral Surg Oral Med Oral Pathol Oral Radiol Endod 94: 717-723, 2002.

17. Johnston PJ, Fisher ER, Rockette HE, et al: The role of thymidylate synthase expression in prognosis and outcome of adjuvant chemotherapy in patients with rectal cancer. J Clin Oncol 12: 2640-2647, 1994.

18. Pestalozzi BC, Peterson HF, Gelber RD, et al: Prognostic importance of thymidylate synthase expression in early breast cancer. J Clin Oncol 15: 1923-1931, 1997.

19. Suzuki M, Tsukagoshi S, Saga Y, Ohwada M and Sato I: Enhanced expression of thymidylate synthase may be of prognostic importance in advanced cervical cancer. Oncology 57: 50-54, 1999. 
20. Metzger R, Danenberg K, Leichman CG, et al: High basal level gene expression of thymidine phosphorylase (platelet-derived endothelial cell growth factor) in colorectal tumors is associated with non-response to 5-fluorouracil. Clin Cancer Res 4: 42371-42376, 1998 .

21. Salonga D, Danenberg KD, Johnson M, et al: Colorectal tumors responding to 5-fluorouracil have low gene expression levels of dihydropyrimidine dehydrogenase, thymidylate synthase and thymidine phosphorylase. Clin Cancer Res 6: 1322-1327, 2000.

22. Chomczynski P and Sacchi N: Single-step method of RNA isolation by acid guanidinium thiocyanate-phenol-chloroform extraction. Anal Biochem 162: 156-159, 1987.

23. Etienne MC, Cheradame S, Fischel JL, et al: Response to fluorouracil therapy in cancer patients: the role of tumoral dihydropyrimidine dehydrogenase activity. J Clin Oncol 13: 1663-1670, 1995
24. Johnston PG, Lenz HJ, Leichman CG, Danenberg KD, Allegra CJ, Danenberg PV and Leichman L: Thymidylate synthase gene and protein expression correlate and are associated with response to 5 -fluorouracil in human colorectal and gastric tumors. Cancer Res 55: 1407-1412, 1995.

25. Chu E, Koeller DM, Casey JL, et al: Autoregulation of human thymidylate synthase messenger RNA translation by thymidylate synthase. Proc Natl Acad Sci USA 88: 8977-8981, 1991.

26. Pullarkat ST, Stoelmacher J, Ghaderi V, et al: Thymidylate synthase gene polymorphism determines response and toxicity of 5-FU chemotherapy. Pharmacogenomics J 1: 65-70, 2001.

27. Keyomarsi K, Samet J, Molnar G and Pardee AB: The thymidylate synthase inhibitor, ICI D1694, overcomes translational detainment of the enzyme. J Biol Chem 268: 15142-15149, 1993. 